\title{
Curto-Circuito na Escola
}

\section{Kaleandra C. Almeida, Ana Carolina Marcelino, Antony B. Turra, Luciana B. Frigo, Eliane Pozzebon}

\author{
LabTeC- Universidade Federal de Santa Catarina(UFSC) \\ Araranguá - SC - Brazil \\ meninasdigitaisufsc@gmail.com, luciana.frigo@ufsc.br
}

\begin{abstract}
This paper describes a report on experiences about electric circuit workshops for high school girls. The workshop has basic concepts about electricity where experimentation is the key point for building dynamic activities. The girls are divided into small groups and they use didactic kits with colorful pieces that can be assembled and connected in many ways, making the experience easy and secure. This workshop is part of a project that aims to present various professions related to technology, engineering and computing that can offer great job opportunities for women who are interested in any of these areas.
\end{abstract}

Resumo. Este artigo apresenta a descrição de um relato de experiência de uma oficina de circuitos elétricos para alunas do ensino médio de escola pública. A oficina abordou conceitos básicos de eletricidade, onde a experimentação é ponto chave para a dinâmica das atividades. As alunas foram divididas em pequenos grupos e foram utilizados kits didáticos com o conceito de blocos de encaixar, o que torna a atividade mais fácil e segura. Esta oficina faz parte do escopo de um projeto que tem por finalidade apresentar diversas profissões relacionadas a tecnologia, engenharia e computação que podem oferecer ótimas oportunidades de trabalho para as mulheres que tiverem interesse por alguma destas áreas.

\section{Introdução}

Aulas práticas devem ser o ambiente propício para o questionamento e para a transformação dos fatos em evidências. Este artigo apresenta um relato de experiência sobre a utilização do kit educacional de circuitos elétricos Snap Circuits em uma oficina realizada com alunas do ensino médio de escola pública apresentando conceitos básicos de eletricidade, com ênfase na associação de resistores e capacitores. A oficina faz parte de uma série de atividades extracurriculares, com alunas do ensino médio, com o intuito de apresentar profissões que envolvam tecnologia e computação. Acredita-se que muitas meninas desconhecem as carreiras nas áreas de tecnologia o que acaba excluindo estas áreas no momento da tomada de decisão para uma escolha profissional.

O ensino de circuitos elétricos na prática é descrito no projeto de (HERTZ \& HAYER, 2013) como uma atividade que pode auxiliar as minorias a como um meio para aumentar sentimentos de empoderamento, autoestima e encantamento pela busca do conhecimento. 
Outro artigo que trata de tema semelhante é de Rebelo e Ramos (2009) que apresenta um relato de investigação sobre o processo de aprendizagem de circuitos elétricos, no Ensino Médio, contando, principalmente, com o auxílio de simulações e de maquetes.

A necessidade de mão de obra qualificada e de profissionais com bons conhecimentos de ciência e tecnologia é cada vez maior. A carência de profissionais é bastante elevada e passa a ser ainda mais preocupante quando se olham os números referentes à participação feminina nestas áreas. Segundo o relatório do Instituto Nacional de Estudos e Pesquisas Educacionais Anísio Teixeira (Inep), dos 1.683 engenheiros da computação formados em 2010, somente 161 eram mulheres. Dados de 2013 enfatizam que as mulheres continuam dando preferência de escolha nas áreas do conhecimento tradicionalmente "femininas", como educação (pedagogia), saúde (enfermagem, psicologia, fisioterapia) e bem-estar social (serviço social) destaque pra área de arquitetura que apresenta significativa participação feminina, enquanto a preferência masculina recai principalmente em cursos de engenharia e tecnologia (MOREIRA, MATTOS \& SILVA, 2014).

Em virtude do contexto sócio-cultural que este quadro se apresenta, existe hoje um movimento mundial com o objetivo de resgatar estas meninas que por um motivo ou outro perdem o interesse em atuar em tecnologia, computação e engenharias, mesmo sendo uma área tão promissora e carente de profissionais qualificados.

O Projeto Meninas Digitais - UFSC propõe atividades atraentes e interativas que mostram que o ensino de computação e engenharia pode ser lúdico e motivador para alunas do ensino médio. Também atua em conjunto para avançar na formação escolar, já que ajuda a desenvolver a criatividade, concentração, raciocínio lógico, objetividade e procura desmistificar essa área, para que mais mulheres atuem nas áreas de STEM(Ciência, Tecnologia, Engenharia e Matemática).

\section{Metodologia}

Este relato foi escrito a partir da oficina realizada na Escola Estadual Básica Dite Freitas na cidade de Tubarão no estado de Santa Catarina. A oficina foi realizada em um único dia, com a duração de três horas. Um conteúdo básico de eletricidade foi apresentado para alunas no ensino médio. As atividades aconteceram no turno vespertino, todas as alunas faziam parte do ensino integral. Participaram da oficina oito alunas que foram selecionadas pela própria escola.

Com o objetivo de verificar o conhecimento prévio das alunas foi realizado um questionário inicial. Após o questionário foi feita uma explicação sobre os conceitos envolvidos e na sequência um primeiro contato com o circuito elétrico que havia sido levado para a sala de aula. Durante a oficina as alunas puderam realizar uma série de experimentos didáticos que são propostos nas apostilas disponibilizadas pelo fabricante dos kits. Os experimentos são classificados em básicos, médios e difíceis. Os kits educacionais são desenvolvidos de forma a tornar o ensino atraente e motivador, são classificados como brinquedos.

Snap Circuits (SNAPCIRCUITS, 2016) é um kit educacional que faz uso de componentes eletrônicos reais onde as conexões são feitas por encaixe, conforme ilustra a Figura 1. Seguindo o conceito de aprender fazendo é uma forma importante de 
assimilação de conteúdos e desenvolvimento da aprendizagem. Eletricidade é um tema pouco aprofundado no ensino médio, o seu estudo é mais recorrente em cursos superiores de graduação, o Snap Circuits preenche uma lacuna, onde se podem simular circuitos elétricos reais, de forma fácil e segura. O Snap Circuits permite que os alunos exercitem conceitos de física e matemática de uma maneira menos abstrata e enfadonha.

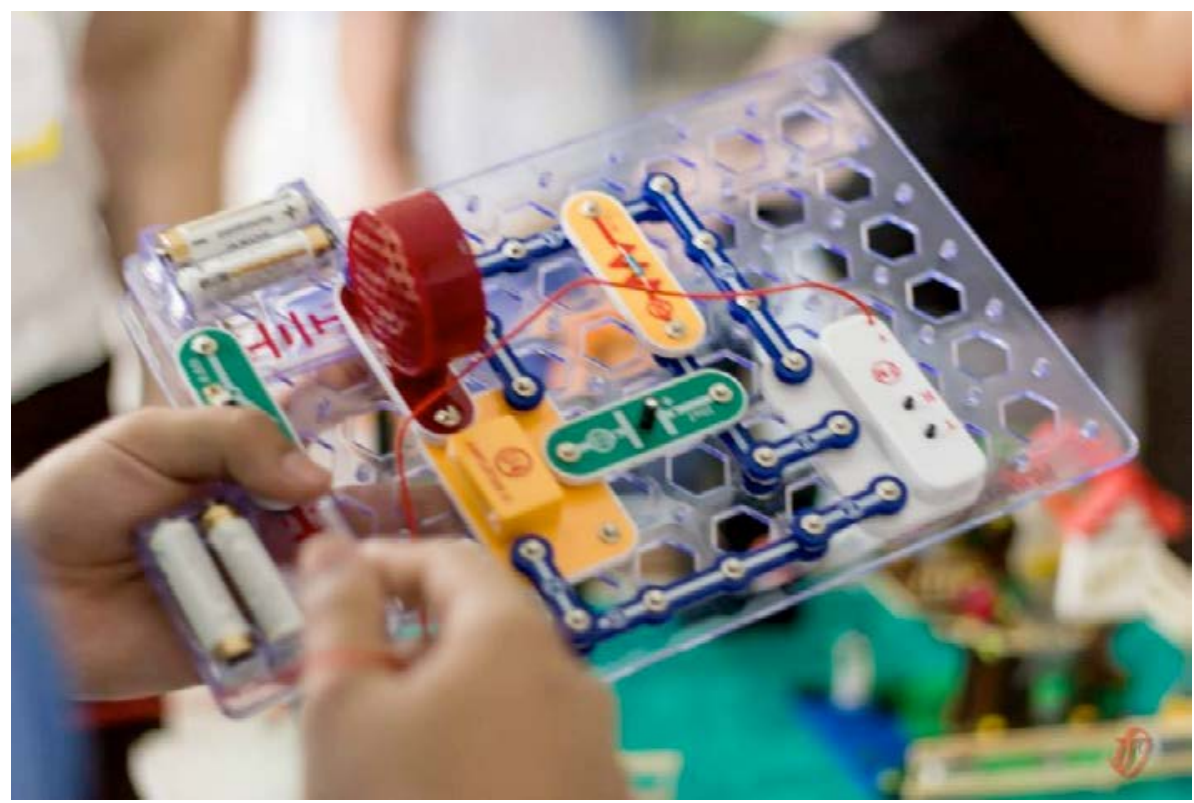

Figura 1. Circuito Elétrico com Snap

Professores e monitores estão disponíveis no tempo da oficina para auxiliarem as alunas na montagem dos circuitos. Os monitores são alunas de graduação, entre bolsistas e voluntárias, da universidade, participam quatro alunas, sendo assim duas voluntárias, duas bolsistas e uma professora.

\section{Resultados e Considerações}

Os resultados da oficina são resultados qualitativos baseados nas respostas das alunas a um questionário. Na oficina realizada foi possível perceber o quanto nossas escolas carecem de atividades de experimentação, todas as alunas afirmaram que a experiência trará benefícios no seu aprendizado, pois o uso dos kits didáticos tornou o aprendizado mais interessante e podem refletir de alguma forma no desempenho escolar delas. Os principais comentários foram: "interessante", "interessante e criativo", "muito legal", "divertida, dinâmica e interessante", "muito legal, amei", etc. Das 8 alunas que participaram da oficina, 7 delas demonstraram querer conhecer mais sobre os circuitos elétricos.

O uso das ferramentas para a oficina despertou o interesse das alunas, provando que antes da oficina, como apresenta os dados do questionário inicial, nenhuma tinha uma opinião formada sobre os circuitos elétricos. Assim, as oficinas despertaram o interesse de aprendizagem, sendo que a facilidade de auxílio das ferramentas propostas na atividade contribuiu para prender a atenção das estudantes, visto que nenhuma das alunas teve dificuldade para realizar os experimentos. No final foi feito um 
questionamento solicitando sugestões para melhoria da oficina. A maior exigência foi o acréscimo da carga horária das atividades propostas, para que elas possam experimentar mais

As participantes do curso, independente de já terem feito suas escolhas profissionais e estarem ou não voltadas às áreas da tecnologia computacional, participaram ativamente da oficina e dos desafios apresentados. Com os experimentos realizados, as estudantes puderam observar o comportamento de alguns circuitos elétricos, como para o funcionamento de rádios e o acionamento de lâmpadas. Além do aprofundamento da física, há também o desenvolvimento do raciocínio lógico, tanto para problemas do cotidiano, quanto para resolução de problemas específicos.

Espera-se que iniciativas para mudar o abismo de gênero nestas áreas se multipliquem cada vez mais, tentando com isso, desmistificar o paradigma que estas áreas são apenas para meninos. No entanto, para superar esta situação são necessários esforços conjuntos de toda a sociedade, que precisa perceber que a diversidade de gênero, de comportamentos e de culturas trará muitos benefícios.

\section{Agradecimentos}

Agradecemos o apoio do CNPq/VALE S.A. N $\mathrm{N}^{\mathrm{o}}$ 05/2012 - Forma-Engenharia, MCTI/CNPq/SPM-PR/Petrobras n ${ }^{\circ}$ 18/2013 e ao Edital Probolsa 2014 da Universidade Federal de Santa Catarina.

Agradecemos também a Escola Jovem Dite Freitas - Tubarão/SC e ao Instituto Alcoa.

\section{Referências}

MOREIRA, J.; MATTOS, G.; SILVA, L. (2014) Um Panorama da Presença Feminina na Ciência da Computação. Disponível em: $<$ http://www.ufpb.br/evento/lti/ocs/index.php/18redor/18redor/paper/view/1935/853 >. Acesso em 12 out. 2015.

REBELLO, A. P. e RAMOS M. G. (2009) Simulação computacional e maquetes na aprendizagem de circuitos elétricos: um olhar sobre a sala de aula. Experiências em Ensino de Ciências - V4(1), pp.23-33, Porto Alegre.

HERTZ, G., Guimarin, A. \& HAYES, G. (2013) Toy Hacking- Preliminary Results in Creative Electronic Workshops for Informal Science Education. FabLearn 2013: Digital Fabrication in Education Conference. October 27-28, 2013.

SNAPCIRCUITS. (2016) Make Learning a Snap. Disponível em: < http://www.snapcircuits.net> Acesso em 31 maio 2016 